\title{
Factors Influencing Diaper Dermatitis Among Jordanian Children Younger Than 24 Months
}

\author{
Eman Alsatari ${ }^{1}$, Nihaya Al-sheyab ${ }^{2}$, Huda Gharaibeh ${ }^{2}$, and Audai Hayajneh ${ }^{3}$ \\ ${ }^{1}$ King Saud Medical City \\ ${ }^{2}$ Affiliation not available \\ ${ }^{3}$ Jordan University of Science and Technology
}

December 9, 2020

\begin{abstract}
Background: Diaper dermatitis (DD) is a highly common condition among neonates, infants, and toddlers. The current study aims to explore the factors influencing DD among children aged between 0-24 months in Jordan. Methods: This study utilized a descriptive cross-sectional design with a convenient sample of 140 children diagnosed with DD. Structured face-to face interviews were used to collect data from the parents of the children included in the study. Univariate and multivariate logistic regression analyses were used to test the association between diaper dermatitis and its related medical factors. Results: The prevalence of DD was found to be $98.6 \%$ among the participants. The median of the duration of the most recent DD episode in days was 3 days (Inter Quartile Range $=2$ to 4 days). The factors influencing DD were the use of barrier cream (OR=.35, 95\% CI $=.18-.72, \mathrm{p}=.004)$, and bathing frequency of [?] 1 time per week $(\mathrm{OR}=1.15,95 \% \mathrm{CI}=.65-2.10, \mathrm{p}=.002)$. Conclusion: The identified factors should be paid significant attention in order to reduce the prevalence of DD among children aged 24 months or under. Prevention-focused programs which encourage the frequent application of appropriate barrier creams and frequent bathing of more than once a week are needed.
\end{abstract}

\section{Hosted file}

diper dermatitis 6-dec.pdf available at https://authorea.com/users/382014/articles/497961factors-influencing-diaper-dermatitis-among-jordanian-children-younger-than-24-months 